\title{
Intestinal Histoplasmosis with Histoplasma duboisii in a Patient Infected by HIV-1 in Abidjan (Ivory Coast)
}

Eboi Ehui ${ }^{1 *}$, Doukouré $B^{2}$, Kolia-Diafouka $P^{1}$, Aoussi $E^{1}$, Koffi $E^{3}$, Doumbia $A^{1}$, Kouadio $K^{4}$, Eholié $S^{1}$ and Bissagnéné $E^{1}$

${ }^{1}$ Department of Infectious and Tropical Diseases, University Hospital of Treichville, 01 BP V 3 Abidjan 01, Cote d'Ivoire

'Laboratory of Pathology, Faculty of Medical Sciences Abidjan, 01 BP V 166 Abidjan, Cote d'Ivoire

${ }^{3}$ Digestive Surgery Department, University Hospital of Cocody, BP V 13 Abidjan, Cote d'Ivoire

${ }^{4}$ Sainte Anne Marie International Polyclinic (PISAM), 01 BP 1463 Abidjan, Cote d'Ivoire

\begin{abstract}
We report a case of intestinal histoplasmosis with Histoplasma duboisii in a 39-year-old patient infected with HIV-1, admitted to the emergency department due to peritonitis with fever and weight loss. He underwent a right hemicolectomy, and the pre-perforation and ulcerated macroscopic aspect during surgery suggested a malignant tumor. The anatomopathological examination of the specimen removed revealed the presence of inflammatory granulomas containing Histoplasma duboisii yeasts. The evolution was rapidly unfavorable, culminating in the patient's death 12 days after treatment onset with intravenous amphotericin B associated with an antiseptic biantibiotherapy. The authors point out the rarity of intestinal localization of histoplasmosis in patients infected with HIV in Abidjan and the contribution of anatomopathological examination in the diagnosis of this condition.
\end{abstract}

Keywords: Abidjan; Amphotericin B; Intestinal histoplasmosis; HIV-AIDS; West Africa

\section{Introduction}

PAfrican histoplasmosis, or histoplasmosis with Histoplasma duboisii, is a profound and rare mycosis, mostly found in West and Central Africa. It rarely occurs in disseminated form because of its particular tropism for the skin, the lymph nodes and the skeleton, and is rarely associated with HIV [1]. In the Ivory Coast, this condition is rarely described in patients infected with HIV [2]. However, cases of cutaneous and bone localizations of histoplasmosis with Histoplasma duboisii were been recently reported [3-5]. The clinical presentation of histoplasmosis in an HIV patient that we describe in this case has never been reported before in the Ivory Coast.

\section{Observation}

Mr. K.B., age 39, and an Ivory Coast native living continuously in Abidjan, was admitted to the Sainte Anne Marie International Polyclinic of Abidjan on March 10, 2007, for severe abdominal pain and emesis lasting for five days. His temperature was $39.6^{\circ} \mathrm{C}$, his blood pressure at 110/60 $\mathrm{mmHg}$, his pulse at 104 beats/min, and his general condition was altered, associated with conjunctival pallor and dehydration. He presented with diffuse abdominal contracture, evoking peritonitis. The pleuropulmonary, cardiovascular, musculoskeletal and mucocutaneous systems did not reveal any particularity. The lung radiography showed a minimal bilateral pleural effusion, and the unprepared abdomen radiography showed some fluid level in the periphery. Moreover, the patient presented with normochromic normocytic anemia (hemoglobin at $10.8 \mathrm{~g} / \mathrm{dl}$ ), bicytopenia (leukocytes at $2,200 / \mathrm{mm}^{3}$, red blood cells at $2,840,000 / \mathrm{mm}^{3}$ ), and thrombocytosis at $502,000 / \mathrm{mm}^{3}$. The other biological analyses, including hematuria, creatinine, natremia, kalemia, transaminases, glycemia, hemocultures, Widal and Félix serodiagnosis, were normal. An emergency right hemicolectomy was performed. The specimen removed showed an ulcerated and pre-perforation aspect. Colonic continuity was restored during the same operation. Histopathological examination of the specimen revealed an inflammatory granuloma consisting of multinucleated macrophages containing yeast and surrounded by a clear halo, evoking the duboisii variety of Histoplasma. It presented lymphoplasmocytes and polynuclear eosinophils, without histological evidence of malignancy [Figure 1]. The patient was infected with HIV1 with a CD4 count of $49 / \mathrm{mm}^{3}$. The serology of histoplasmosis was not performed. Treatment included a bi-antibiotherapy (ceftriaxone + metronidazole) used as an antiseptic and intravenous amphotericin $\mathrm{B}$ (at $1 \mathrm{mg} / \mathrm{kg}$ every other day). The evolution became rapidly unfavorable, with exitus of the patient on day 12 due to multiple organ failure.

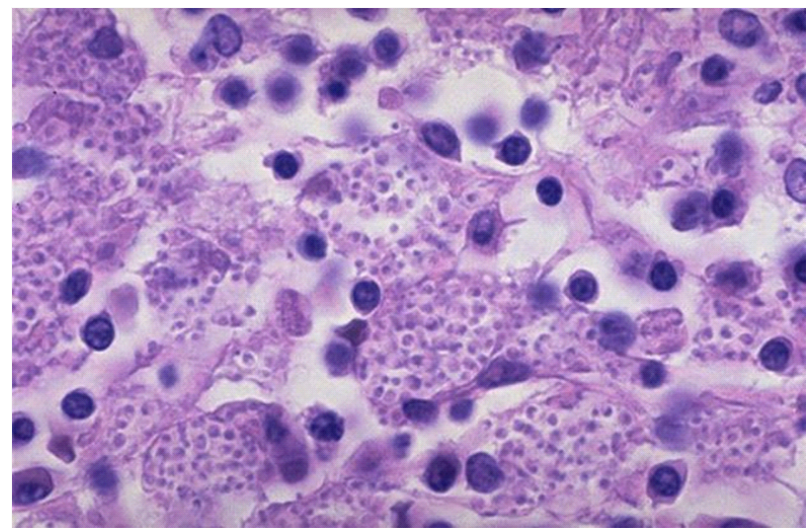

Figure 1: Inflammatory granuloma consisting of lymphoplasmocytes and macrophages containing numerous Histoplasma with a clear halo (hematoxylineosin staining, $\times 400)$.

*Corresponding author: Dr. Eboi Ehui, Department of Infectious and Tropical Diseases, University Hospital of Treichville, 01 BP V 3 Abidjan 01, Cote d'Ivoire, Tel: 225212552 49; Fax: 225212428 52; E-mail: docehui@yahoo.fr

Received March 06, 2011; Accepted September 20, 2011; Published September 25, 2011

Citation: Ehui E, Doukouré B, Kolia-Diafouka P, Aoussi E, Koffi E, et al. (2011) Intestinal Histoplasmosis with Histoplasma duboisii in a Patient Infected by HIV-1 in Abidjan (Ivory Coast). J AIDS Clinic Res 2:125. doi:10.4172/2155-6113.1000125

Copyright: (C) 2011 Ehui E, et al. This is an open-access article distributed under the terms of the Creative Commons Attribution License, which permits unrestricted use, distribution, and reproduction in any medium, provided the original author and source are credited. 
Citation: Ehui E, Doukouré B, Kolia-Diafouka P, Aoussi E, Koffi E, et al. (2011) Intestinal Histoplasmosis with Histoplasma duboisii in a Patient Infected by HIV-1 in Abidjan (Ivory Coast). J AIDS Clinic Res 2:125. doi:10.4172/2155-6113.1000125

\section{Discussion}

In the Ivory Coast, histoplasmosis with Histoplasma duboisii has been rarely described in patients with AIDS [3-5]. This confirms the idea that Histoplasma duboisii, which is mainly found in Africa, is rarely associated with HIV, while Histoplasma capsulatum, which, in its disseminated form, is a definition criterion for AIDS, is common in America [1]. Its rarity in our country is due to many reasons: its clinical polymorphism, which may mislead the clinical diagnosis, as in many observations described in Ivory Coast [3-5]; but also to the unavailability and/or non-systematic use of anatomopathological examination and serological tests. Indeed, the gastrointestinal manifestations (abdominal pain, diarrhea and sometimes blood emesis) are not specific for intestinal histoplasmosis, and can be found in $3 \%$ to $12 \%$ of patients with the disseminated form [6]. Sometimes, it is possible to observe gastrointestinal bleeding, intestinal perforation or even peritonitis, as in our case. For this reasons, Loulergue et al. already suggested that diagnostic of histoplasmosis in African patients should not be discounted because of the HIV status of the patients based on their cases and previous literature review [7]. The reports of many authors support the idea that the low incidence of African histoplasmosis could be due to a problem of under-reporting or underrecognition in Africa [7-9]. In resource limited situation, empirical anti-fungal treatment could be considered in patients with suspected gastro-intestinal histoplasmosis in order to diagnose and to treat this potentially life-threatening infection. The histopathological appearance of histoplasmosis is an inflammatory granuloma rich in epithelial and giant cells circumscribed by lymphoplasmocytes. At the center of the granuloma, there is fibrinohemorrhagic necrosis, or necrosis caseosa, which in our tropical context can guide the diagnosis to a tuberculous lesion [6]. On a morphological level, Histoplasma may be confused with Candida glabrata; Penicillium marneffei, Cryptococcus neoformans, and the amastigote form of trypanosomes, hence the interest in the research of a blood or urine antigen for Histoplasma to facilitate definitive diagnosis. Unfortunately, these diagnostic tests are not available yet in limited resources setting. Many authors have reported cases of disseminated histoplasmosis under antiretroviral therapy related to immune restoration [10-14]. None of these cases have been still reported in Africa. Perhaps, we could then fear a resurgence of this disease in Africa as a result of the current generalization of antiretroviral therapy. According to international recommendations, Amphotericin B is the preferred treatment for disseminated and intestinal histoplasmosis [6] and Itraconazole, for the consolidation phase; but in our context, Itraconazole is not always available. These treatments should improve the prognosis of the disease, whose lethality can in some cases reach $60 \%[9,15,16]$.

\section{Conclusion}

Intestinal histoplasmosis with Histoplasma duboisii is rarely associated with AIDS in the Ivory Coast. This rarity can be due to underreporting or under-diagnostic, and diagnostic difficulties because of the lack of specific clinical sign, and the unavailability of sensitive and specific diagnostic test. In this context, empirical antifongal treatment should be founded in front of evocative clinical signs of intestinal histoplasmosis.

\section{References}

1. Couppie P, Aznarb C, Carme B, Nacher M (2006) American histoplasmosis in developing countries with a special focus on patients with HIV: diagnosis, treatment, and prognosis. Curr Opin Infect Dis 19: 443-449.

2. Grant A, Djoman G, De Cock K M (1997) Natural history and spectrum of disease in adults with HIV / AIDS in Africa. AIDS 11: 633-610.
3. Bankolé SR, Denoulet C, Coulibaly B, Nandiolo R, Kassi E, et al. (1998) About one Ivoirian case of bone and cutaneous histoplasmosis by Histoplasma capsulatum var. duboisii [French]. Bull Soc Pathol Exot 91: 151-153.

4. Sangare A, Yoboué P, Ahogo C, Ecra E, Kaloga M, et al. (2008) Histoplasmosis due to Histoplasma capsulatum var. Duboisii localization and skin associated with AIDS. About one case in Abidjan, Cote d'Ivoire. Bull Soc Path Ex 101: 5- 7.

5. Ahogo KC, Sangaré A, Gbery IP, Ecra E, Kaloga M, et al. (2009) Cutaneous histoplasmosis due to Histoplasma capsulatum variety duboisii in an immune competent child. About one case in Abidjan, Côte d'Ivoire [French]. Bull Soc Pathol Exot 102: 147-149.

6. Suh KN, Anekthananon T, Mariuz PR (2001) Gastrointestinal histoplasmosis in patients with AIDS: case report and review. Clin Infect Dis 32: 483-491.

7. Loulergue P, Bastides F, Baudouin V, Chandenier J, Mariani-Kurkdjian P, et al. (2007) Literature review and case histories of Histoplasma capsulatum var duboisii infections in HIV-infected patients. Emerg Infect Dis 13: 1647-1652.

8. Antinori S, Magni C, Nebuloni M, Parravicini C, Corbellino M, et al. (2006) Histoplasmosis among Human Immunodeficiency Virus-infected people in Europe. Report of 4 cases and review of the literature. Medicine 85: 22-36.

9. McKinsey DS, Spiegel RA, Hutwagner L, Stanford J, Driks MR, et al (1997) Prospective study of histoplasmosis in patients infected with human immunodeficiency virus: incidence, risk factors, and pathophysiology. Clin Infect Dis 24: 1195-1203.

10. Breton G, Adle-Biassette H, Therby A, Ramanoelina J, Choudat L, Bissuel F et al. (2006) Immune reconstitution inflammatory syndrome in HIV-infected patients with disseminated histoplasmosis. AIDS 20: 119-121.

11. Breton G, Dupont B (2005) Immune reconstitution syndrome in systemic mycoses in HIV infected patients [French]. J Mycol Med 15: 77-92.

12. Breton G, Adle-Biassette H, Therby A, Ramanoelina J, Choudat L, et al. (2006) Immune reconstitution inflammatory syndrome in HIV-infected patients with disseminated histoplasmosis. AIDS 20: 119-121.

13. Nacher M, Sarazin F, El Guedj M, Vaz T, Alvarez F, et al. (2006) Increased incidence of disseminated histoplasmosis following highly active antiretroviral therapy initiation. J Acquir Immune Defic Syndr 41: 468-470.

14. Lawn SD, French MA (2007) Immune reconstitution disease: recent developments and implications for antiretroviral treatment in resource-limited settings. Curr Opin HIV AIDS 2: 339-345.

15. de Francesco Daher E, de Sousa Barros FA, da Silva Júnior GB, Takeda CF, Mota RM, et al. (2006) Risk factors for death in acquired immunodeficiency syndrome associated disseminated histoplasmosis. Am J Trop Med Hyg 74: 600-603.

16. Wheat LJ, Chetchotisakd P, Williams B, Connolly P, Shutt K, et al. (200) Factors associated with severe manifestations of histoplasmosis in AIDS. Clin Infect Dis 30: 877-881. 